\title{
Date and Time of Last Study Treatment
}

National Cancer Institute

\section{Source}

National Cancer Institute. Date and Time of Last Study Treatment. NCI Thesaurus. Code C117454.

The date and time of the subject's final study treatment. 